\title{
MILIARY SEBACEOUS CYSTS AND BLISTERS IN THE HEALTHY NEWBORN
}

\author{
BY \\ ISRAEL GORDON, M.D.(Ed.), M.R.C.P.(Lond.), D.P.H. \\ Deputy Medical Officer of Health, Ilford
}

Miliary sebaceous cysts and blisters are probably the commonest neonatal skin disorder (if disorder it be), yet there has apparently been no reference to it in the periodical medical literature of the last thirty-two years, and it is ignored in many textbooks of dermatology and poorly described in others. Warvi and Gates (1943) do not mention the condition in a survey of epithelial cysts. Unna (1896) in his textbook showed the lesions to be sebaceous cysts, and the glands to be hypertrophic and occluded by a thin horny layer. In Macleod's 'Diseases of the Skin' (1933) the association with the sebaceous glands is also mentioned. So far as I am aware, the 'blister' form has not been described before, nor the actual incidence.

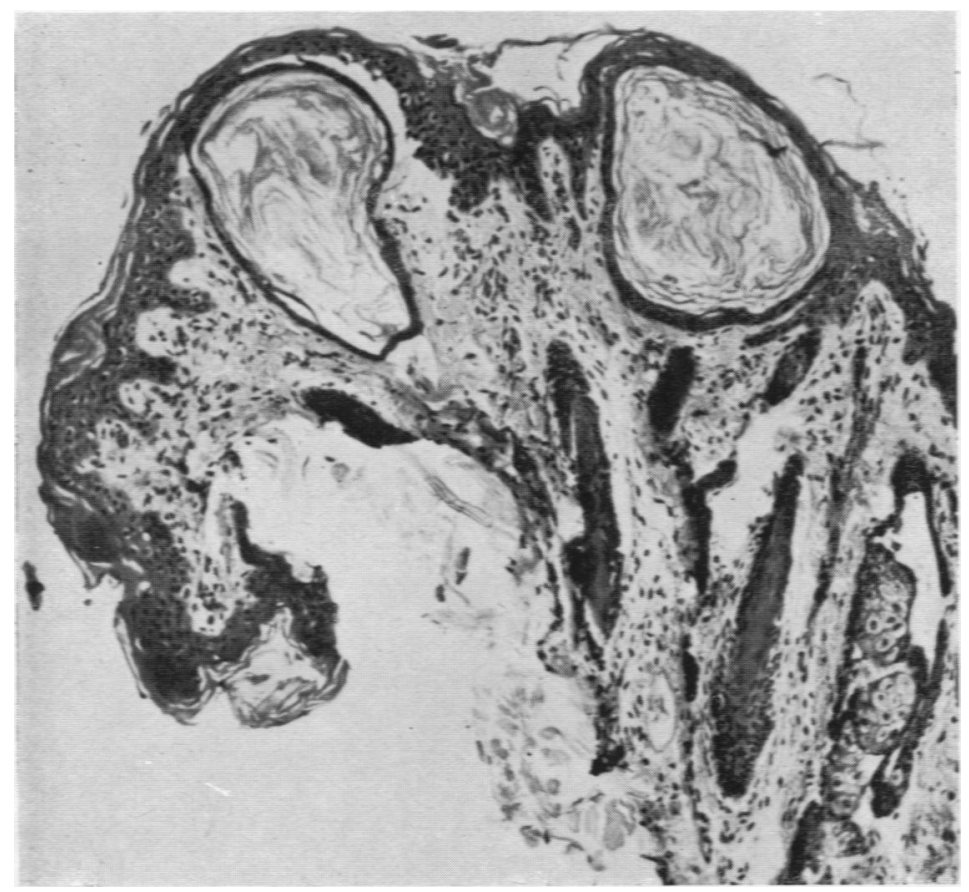

Frg. 1.-Miliary sebaceous cysts. $\times 100$.

\section{Appearance}

The spots are pearly white, about the size of the head of a pin or somewhat smaller. They occur on the cheeks, chin, naso-labial folds, and forehead, and in marked cases may even be found on the upper half of the trunk. There may be only one or two or a dozen or more. Some are in the skin, others are raised above it and superficial. Occasionally one may cap a red papule. Microscopically there appear to be two forms, a typical small sebaceous cyst in the dermis (fig. 1), and a superficial type where the horny layer seems to have overgrown the mouth of the duct and has been raised by the secretion as a sort of sebaceous blister (fig. 2).

\section{Incidence}

The condition apparently arises in foetal life. The spots were present in thirtynine out of one hundred infants examined in the first twenty-four hours after delivery. In the first four weeks of life they were present in sixty out of one hundred and forty-eight infants (41 per cent.); in the second four weeks in thirty-nine out of one hundred and six infants (37 per cent.); in the third four weeks in ten out of forty-eight infants (21 per cent.); and then the incidence drops sharply, the spots being present only in seven out of one hundred and eight infants (6 per cent) in the second three months of life. Some of the spots seem to be absorbed, others, presumably the superficial ones, dry up and drop off. Similar lesions are found occasionally in adults, who may have a tendency to develop these milia, of an ephemeral nature. I have not included the appearance found in the skin of the tip of the nose of the newborn child in these figures. A white speckling is seen here in nearly all infants, is always deep in the skin, and is presumably the same condition. In the small series available there 
was no difference between breast and bottle fed babies of any statistical significance.

Papules on the face are very common in the first few months of infant life. Their incidence, however, differs altogether from these sebaceous lesions. At birth they were found in only three out of one hundred, in the second month in fiftyseven out of one hundred and six (54 per cent.); thereafter the incidence diminished gradually. Occasionally there may be a cyst or a blister capping a papule, in which case the lesion resembles a small pustule.

\section{Discussion}

That cyst formation in the sebaceous glands begins in foetal life has been shown by Reiss (1932). He states that in the foetus these glands reach a high level of functional activity and excrete so abundantly that the sebum cannot all escape from the ducts, and cyst formation begins. He asserts that the vernix caseosa is partly formed by the secretion of these glands, hence their activity. Macleod (1933) states that they are retention cysts caused by the plugging of a dilated duct by debris. It is easily apparent that in the neonatal form no such plugging takes place as the cyst is capped by a shiny uniform patch of epidermis. It does appear that the glands are highly developed in foetal life, probably to help to form the vernix caseosa, but eventually the normal skin grows over the ducts of many of the glands, thus closing them. Further secretion ensues and a cyst forms.

Sutton (1939), discussing these milia in adults, mentions that in many cases there is a history of excessive drinking of milk. I have corroborated this in some cases, if fat-eating be added to milkdrinking. Even in these times of rationing some people with sufficient desire for fat can obtain extra quantities. The secretion of the sebaceous glands contains much cholesterol (Reiss, 1932; Montagna and Noback, 1947); lanolin, an analogous excretion, is similarty largely constituted of cholesterol. Milk contains much cholesterol; the human infant, in fact, weight for weight, ingests an amount of cholesterol almost comparable to that given to experimental rabbits, in whom hypercholesterolaemia and atheroma results. In fact Kube and Ssolowjew (1930) found that lipoid deposition in the intima of aortae of infants did begin to occur shortly after birth and attributed this to the high cholesterol diet. The amount of cholesterol in the nutriment the foetus obtains from the mother is of course unknown, but Wislocki and Bennett (1943) state that cholesterol does pass the placenta, in contradistinction to neutral fat, which probably does not. It seems not improbable then that the foetus has a high level of cholesterol metabolism, when endogenous production is considered as well. The fact that the serum cholesterol of the newborn is low (60 mgm. per cent., Hueper, 1945), probably

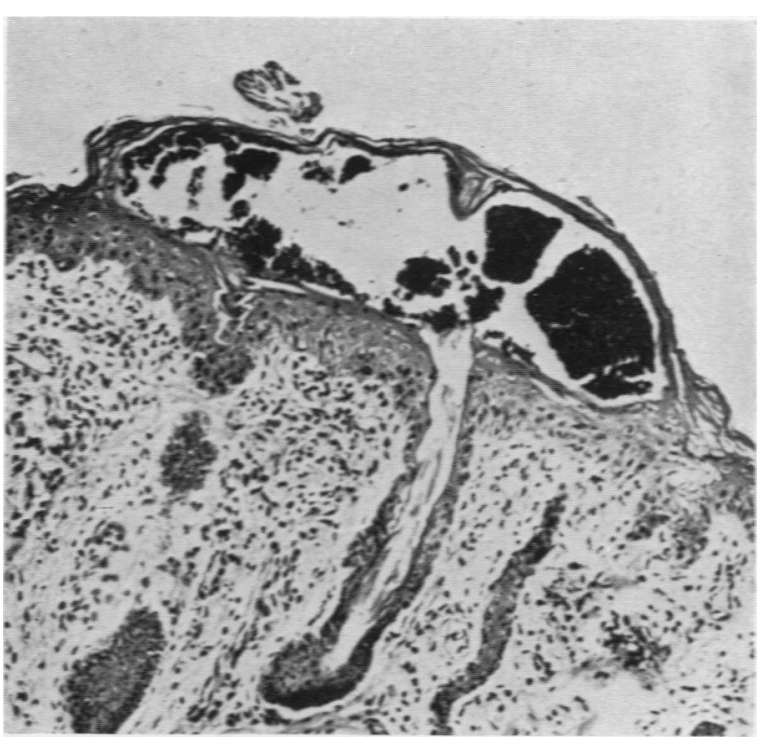

Fig. 2.-Miliary sebaceous blister. $\times 100$.

means that it is utilized as quickly as it is delivered, so it cannot accumulate in the blood, as it begins to do shortly after birth. Perhaps one way in which it is used up is in the formation of a sebaceous secretion to be passed in the vernix caseosa.

\section{Summary}

1. Approximately $\mathbf{4 0}$ per cent. of healthy newborn infants present milia, mainly on the face.

2. These milia are miliary sebaceous cysts and blisters, and have probably resulted from the epidermis overgrowing the ducts of sebaceous glands.

3. In foetal life the sebaceous glands are highly active, perhaps to help to form the vernix caseosa.

4. The incidence of these cysts and blisters gradually diminishes, and becomes negligible by the second three months of life.

5. There may be some relationship between activity of these sebaceous glands and cholesterol metabolism.

The work for this paper was carried out in the infant welfare centres and Maternity Home of the borough of Ilford, and for facilities there I am indebted to Dr. J. H. Weir.

\section{REFERENCES}

Hueper, W. C. (1945). Arch. Path., 39, 187.

Kube, N., and Ssolowjew, A. (1930). Frankfurt. $Z$. Path., 40, 302. 
Macleod, J. M. H. (1933). 'Diseases of the Skin.' Unna, P. G. (1896). 'The Histopathology of the London.

Diseases of the Skin.' Edinburgh.

Montagna, W., and Noback, C. R. (1947). Amer. J. Warvi, W. N., and Gates, O. (1943). Amer. J. Path., Anat., 81, 39. $19,765$.

Reiss, H. (1932). Arch. Derm. Syph. Wien, 166, 30.

Sutton, R. L., and Sutton, R. L., Jr. (1939). 'Diseases of the Skin.' St. Louis.

Wislocki, G. B., and Bennett, H. S. (1943). Amer. J. Anat., 73, 335. 